University of Nebraska - Lincoln

DigitalCommons@University of Nebraska - Lincoln

1981

\title{
Forecasting Reject Rate of Tested LSI Chips
}

Sharad C. Seth

University of Nebraska-Lincoln, seth@cse.unl.edu

Vishwani D. Agrawal

Bell Laboratories, Murray Hill, NJ

Follow this and additional works at: https://digitalcommons.unl.edu/csearticles

Part of the Computer Sciences Commons

Seth, Sharad C. and Agrawal, Vishwani D., "Forecasting Reject Rate of Tested LSI Chips" (1981). CSE Journal Articles. 40.

https://digitalcommons.unl.edu/csearticles/40

This Article is brought to you for free and open access by the Computer Science and Engineering, Department of at DigitalCommons@University of Nebraska - Lincoln. It has been accepted for inclusion in CSE Journal Articles by an authorized administrator of DigitalCommons@University of Nebraska - Lincoln. 


\title{
Forecasting Reject Rate of Tested LSI Chips
}

\author{
S. C. SETH, MEMBER, IEEE AND V. D. AGRAWAL, SENIOR MEMBER, IEEE
}

\begin{abstract}
The reject rate of LSI chips due to incomplete fault coverage of the tests is the fraction of faulty chips among the chips that pass the tests. This reject rate, which is a measure of the tested chip quality, contributes to the field returns. It is, however, difficult to determine the tested chip quality from the field return data which may also include rejects due to handling damages, infant mortality, etc. Also, a large number of chips must be in use in the field before an adequate amount of field return data can be obtained. This paper gives a method of forecasting the reject rate from the test data alone before any field trials are made.
\end{abstract}

\section{BACKGROUND}

In a recent paper [1], the reject rate of the tested chips was obtained as

$$
r(f)=\frac{(1-f)(1-y) e^{-\left(n_{0}-1\right) f}}{y+(1-f)(1-y) e^{-\left(n_{0}-1\right) f}}
$$

where $f=$ fault coverage of tests

$n_{0}=$ average number of faults on a defective chip (as explained in [1], $n_{0}$ is different from the defect density that is normally used in yield analysis)

and $y=$ true yield of good chips.

For computing $r(f)$, the yield was assumed to be known and the parameter $n_{0}$ was evaluated from test data. In today's rapidly changing technology, however, the yield is not always known. In fact, true yield can be estimated only after the chip has been in production for some time. This paper presents an application of a forecasting technique for evaluation of yield and reject rate from the test data.

\section{BASIC IDEA}

A complete fault coverage is usually not possible for LSI tests. Typical experimental data are shown in Fig. 1 (see Table 1 of [1]). This graph shows the fraction of the manufactured chips that are rejected as the fault coverage is increased. In this case the testing stops at $65 \%$ fault coverage. The basic idea behind the present work is to predict or forecast how the fraction of rejected chips will continue to grow if testing was extended to $100 \%$ fault coverage. Using the parameters $y$ and $n_{0}$, as defined above, the theoretical probability of rejecting a chip with tests having a fault coverage $f$ was obtained in [1] as

$$
P(f)=(1-y)\left[1-(1-f) e^{-\left(n_{0}-1\right) f}\right] \text {. }
$$

We will now estimate $y$ and $n_{0}$ such that the forecast error in $P(1)$ is minimized.

Manuscript received August 3, 1981; revised September 2, 1981. S. C. Seth is with the Department of Computer Science at the University of Nebraska, Lincoln, NB 68588 ; V. D. Agrawal is with Bell Laboratories, Murray Hill, NJ 07974.

\section{Weighted LEAst MeAn SQUaRed Estmation}

The mean squared error for fitting $P(f)$ to the experimental data is defined as [2]

$$
\text { MSE }=\sum_{i=1}^{k}\left[P\left(f_{i}\right)-P_{i}\right]^{2} \cdot a^{100}\left(f_{\max }-f_{i}\right),
$$

where $\left(f_{i}, P_{i}\right), i=1, \ldots k$, are the experimental data as shown in Fig. 1 and $f_{\max }$ is the maximum fault coverage up to which experimental data are available (0.65 in Fig. 1). The last factor is known as the weighting factor. Notice that $a=1$ corresponds to the unweighted mean squared error while $0<a<1$ weights the error nearer to $f_{\max }$, heavier. From (2), since $P(1)=1-y$, we should select the value of the weighting parameter, $a$, such that the variance of $y$ is minimized. There are several procedures which minimize (3) and then find the variance of estimated parameters[3]. In practice, many nonlinear search computer routines are available. We will illustrate the procedure by using the nonlinear estimation program known as NLIN (Non-LINear regression) [4]. The program first performs a coarse search of the parameter space to determine starting values, and then uses an iterative method to minimize the weighted mean square error. For the data of Fig. 1, this program gave the values of $y$ and $n_{0}$, which minimize (3), as shown in Fig. 2. The program also provides the $95 \%$ confidence intervals for the parameters shown as the shaded region in the figure. As the value of the weighting parameter $a$ was reduced, the $95 \%$ intervals continue to become narrower until at $a=0.55$, the parameter values and their ranges are

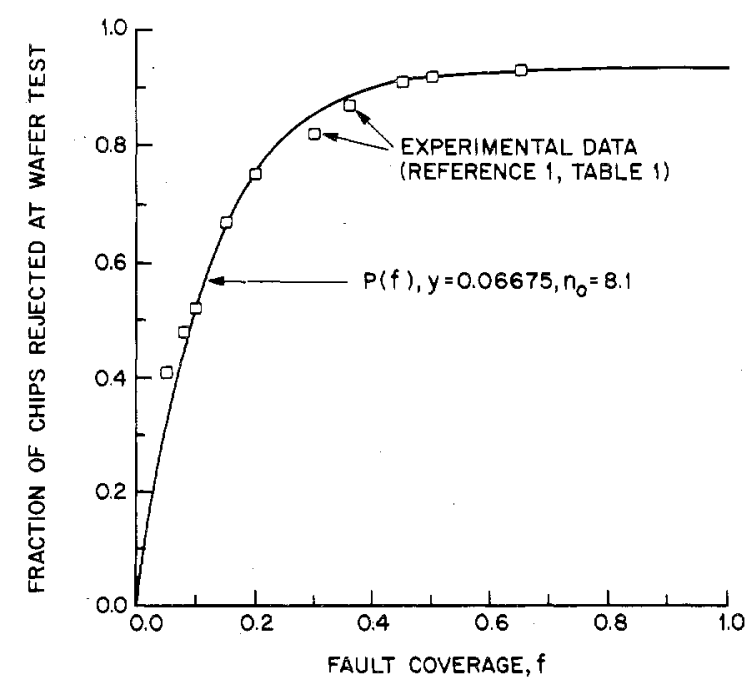

Fig. 1. Wafer test data: fraction of chips rejected as a function of fault coverage of tests. The continuous curve corresponds to the probability of rejecting the chip computed from the estimated parameters $y=0.06675$ and $n_{0}=8.1$. 

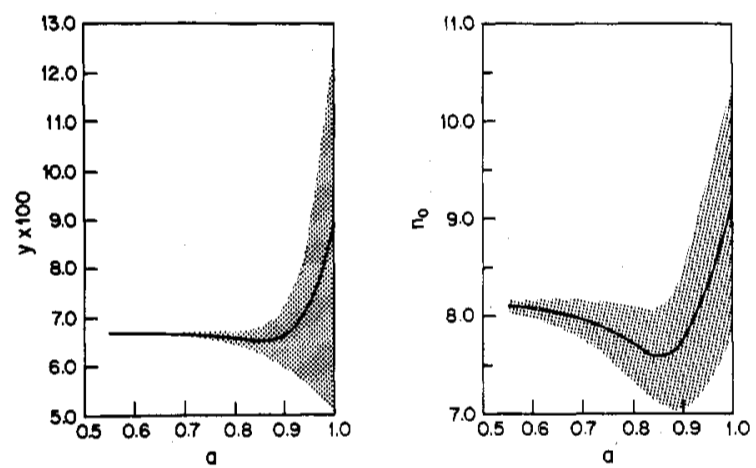

Fig. 2. Estimated parameters $y$ and $n_{0}$ (solid curves) and their $95 \%$ confidence intervals (shaded regions) as functions of the weighting parameter $a$.

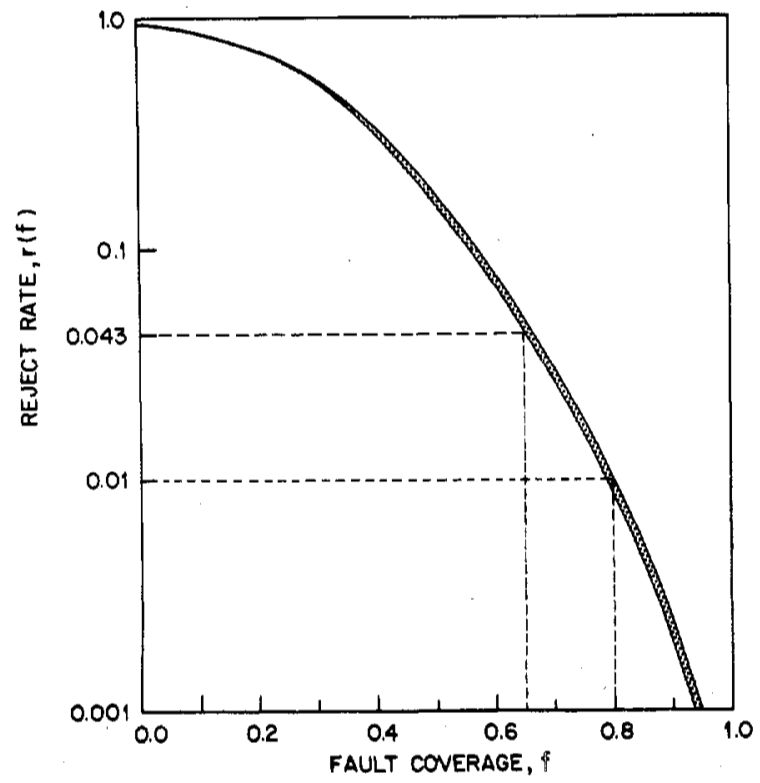

Fig. 3. Reject rate as computed from the estimated parameters. For $95 \%$ confidence interval of parameters, $y=0.06675 \pm 0.00015$ and $n_{0}=8.10 \pm 0.09$, the reject rate lies in the shaded region. stabilized and no further change in $a$ was considered necessary. The best fit values of the parameters are $y=0.06675$ and $n_{0}=8.1$ with the $95 \%$ confidence ranges being \pm 0.00015 and \pm 0.09 , respectively. The best fit $P(f)$, as computed from (2), is shown in Fig. 1 as the continuous curve.

Figure 3 shows the reject rate as computed from (1). For the $95 \%$ range of $y$ and $n_{0}$, the reject rate would be in the shaded region in the figure. This gives a $4.3 \%$ reject rate for the $65 \%$ fault coverage. The fault coverage should be increased to $80 \%$ for a $1 \%$, and to $95 \%$ for a $0.1 \%$ reject rate. These results are substantially in agreement with those obtained in [1]. We have, however, removed the need for the prior knowledge of the yield. In fact the estimated yield of $6.6 \%$ is fairly close to the yield of $7 \%$ used in [1].

\section{CONCLUSION}

A nonlinear parameter estimation is used to forecast the reject rate of the tested LSI chips from the functional test data. In this procedure the chip yield is also estimated. This method can be used to study the LSI test quality even before the product is sent into the field. The result also helps in deciding whether the fault coverage of tests is adequate or needs to be improved.

\section{ACKNOWLEDGMENT}

The NLIN program for this work was run by J-Y. Juang.

\section{REFERENCES}

[1] V. D. Agrawal, S. C. Seth, and P. Agrawal, "LSI product quality and fault coverage," Proceedings of 18 th Design Automation Conference, Nashville, TN, pp. 196-203, June 29 - July 1, 1981.

[2] W. Gilchrist, Statistical Forecasting, Chichester, U.K.: Wiley Interscience, 1976.

[3] Y. Bard, Nonitinear Parameter Estimation, New York: Academic Press, 1974.

[4] SAS User's Guide, Cary, NC: SAS Institute, Inc., pp. 317-329, 1979. 